\title{
The Future is now!
}

\section{Carlo Melloni*}

Department of Surgical, Oncological and Oral Sciences, Plastic and Reconstructive Surgery Unit, University of Palermo, Italy

*Corresponding author: Carlo Melloni, M.D, Department of Surgical, Oncological and Oral Sciences, Plastic and Reconstructive Surgery Unit, University of Palermo, Italy, Tel: +39 091 6554034; Fax: +39 091 6553720; E-mail: carlomelloni.unipa@gmail.com

Received date: June 26, 2015, Accepted date: June 28, 2015, Published date: June 29, 2015

Copyright: ( 2015 Melloni C. This is an open-access article distributed under the terms of the Creative Commons Attribution License, which permits unrestricted use, distribution, and reproduction in any medium, provided the original author and source are credited.

\section{Editorial}

Countdown to suspense and video with special effects introduced the EuRePS Meeting's opening, on $18^{\text {th }}$ June 2015. The conference, entirely dedicated to European Residents in Plastic Surgery, has been organized by the School of Specialization in Plastic, Reconstructive and Aesthetic Surgery of the University of Palermo (Figure 1).

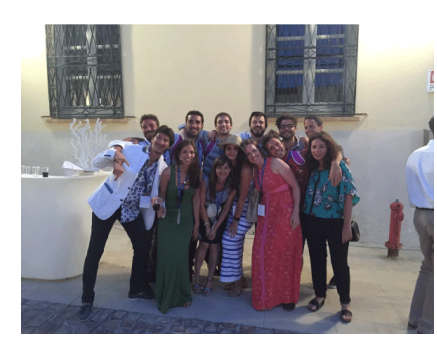

Figure 1: The organizing committee.

The setting was that of Favignana, an enchanting, whimsical, harsh and welcoming island in the Mediterranean Sea. About 150 participants from all over Europe and beyond have invaded the venue of the meeting, an old tuna-fish factory called "Tonnara Florio" (Figure 2).

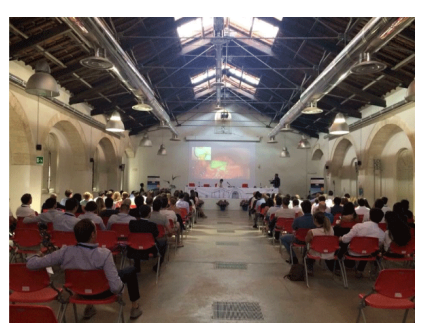

Figure 2: The hall full of residents coming from all over the Europe and beyond.

The enthusiasm is sky high and the focus is at the top. Off we go!

With their communications and high quality scientific works, the Residents gave birth to four days of intense debate on the most advanced researches in plastic surgery (Figure 3 ).

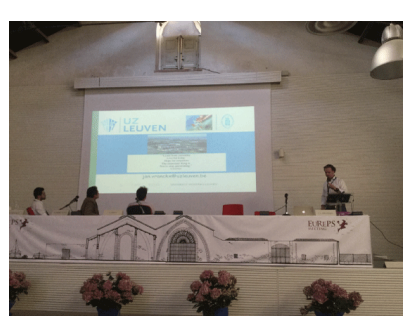

Figure 3: Jan Jeroen Vranckx froma Leuven speaking about new perspectives in Plastic Surgery.

Sharing knowledge and setting new collaborations were the main goals of the meeting. Attendants presented their works, both in podium and in poster presentation, and residents also had the opportunity to be moderators for one day tutored by the Directors of the Italian Schools of Plastic Surgery.

The poster session was one of the greatest innovations. With a fresh and informal format, the poster session was arranged as a short-oralpresentation during an aperitif. Speakers presented their works in 3 minutes enjoying together with the attendant a glass of icy-white-wine.

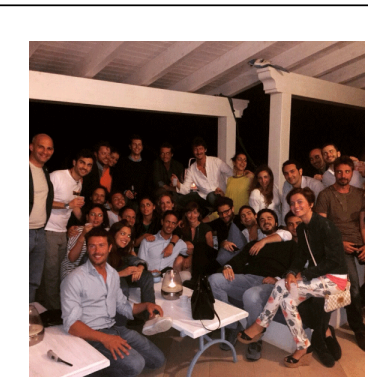

Figure 4: After the science here comes the fun.

The Keynote Lectors of the invited "Special Guest" such as Roy De Vita (Rome), Jaume Masia (Barcelona), Fabio Santanelli Pompey (Rome), Jan Vranckx (Leuven) and Salvatore D'Arpa (Gent) have enriched the scientific program with important practical information, charming the participants with their "ars oratoria".

The event ended on Sunday 21st with a space reserved for the projects of the Italian Society of Plastic, Reconstructive and Aesthetic Surgery (SICPRE) dedicated to residents and the awards for the best five works.

The EuRePS Award for the best communication went to Margot Den Hondt, resident in Leuven (Belgium), who will have the 
Citation: Melloni C (2015) The Future is now! Anaplastology 4: e114. doi:10.4172/2161-1173.1000e114

Page 2 of 2

opportunity to participate for free at the upcoming EURAPS meeting in Brussels in 2016.

In this way, four unforgettable days of science, friendship and fun come to the end: the perfect mix that made this event unique (Figure $4)$.
We are looking at the future; we are looking for a new way to arrange meetings in a different format: less formal, relaxed atmosphere and smart presentations with lots of tips and tricks messages to take home. As The Offspring says...The future is now! 